\section{SST2: a new kid on the block for patients with ACHD}

\author{
Oktay Tutarel $\left.\right|^{\odot}$
}

Adults with congenital heart disease (ACHD) are an increasing and ageing population. ${ }^{1}$ Despite all advances in medical and surgical treatment, patients with ACHD are still afflicted by significant morbidity and mortality. ${ }^{2}$ Timely identification of those patients that are at risk can be difficult. In acquired cardiovascular disease, biomarkers play an important role for the diagnosis and even for monitoring the treatment. Brain natriuretic peptides, which are firmly established in the diagnosis and management of heart failure due to acquired cardiovascular disease, have value in patients with ACHD, but are burdened with some limitations, for example, no real cut-off values due to the pathophysiological variety of the underlying congenital heart defects. Furthermore, brain natriuretic peptide values can differ widely, hence conclusions for individual patients can only be drawn with caution. ${ }^{3}$ Therefore, the search for other biomarkers for the diagnosis and management of patients with ACHD continues. ${ }^{4}$ Ideally, such a biomarker would give us a more comprehensive insight into the pathophysiology than brain natriuretic peptides. One candidate is soluble suppression of tumorigenicity 2 (sST2), which is the circulating form of the cellular receptor ST2L. ${ }^{5}$ ST2 is the receptor for interleukin-33 (IL-33). ${ }^{6}$ The interaction of IL-33 and ST2L is cardioprotective in experimental models, reducing myocardial fibrosis, cardiomyocyte hypertrophy and apoptosis. ${ }^{6}$ This cardioprotective action occurs only through the ST2L receptor, while sST2 binds to IL-33 competing with ST2L, hence blocking the IL-33/ST2L system and eliminating the cardioprotective effects. ${ }^{6}$ It has been established that SST2 is a predictor of both all-cause mortality and cardiovascular death in stable chronic heart failure

Department of Paediatric Cardiology and Congenital Heart Disease, German Heart Centre Munich, Munich, Germany

Correspondence to Dr. Oktay Tutarel, Department of Paediatric Cardiology and Congenital Heart Disease, German Heart Centre Munich, Munich 80636, Germany; otutarel@hotmail.com outpatients $^{5}$ as well as all-cause mortality and heart failure rehospitalisations in patients with acute heart failure independent of brain natriuretic peptides. ${ }^{7}$ Interestingly, sST2 levels appeared to elevate several weeks before the time of the primary endpoint in the latter study. ${ }^{7}$ Its role in patients with ACHD is unknown. Geenen and colleagues measured sST2 in patients with ACHD with a variety of defects. ${ }^{8}$ While sST2 was associated with the primary endpoint-a composite of all-cause mortality, heart failure, hospitalisation for cardiac reason, arrhythmias, thromboembolic events and interventions-and the secondary endpoint (all-cause mortality and heart failure) in a univariate analysis, this association was not significant after adjustment for N-terminal pro-B-type natriuretic peptide (NT-proBNP) and clinical variables. The only subgroup in which sST2 remained significantly associated with the endpoints were patients with ACHD with complex disease. ${ }^{8}$ Furthermore, in women, sST2 was associated with the endpoints, but after adjusting for NT-proBNP and clinical variables, the association was not significant anymore. What are the reasons for these mixed and somewhat different results compared with patients with acquired cardiovascular disease? If we take a closer look at the study population of Geenen and colleagues, it is obvious that most of their patients were asymptomatic, that is, in New York Heart Association class I. ${ }^{8}$ Accordingly, the levels of NT-proBNP were not significantly elevated. Furthermore, sST2 was elevated only in around $10 \%$ of patients. Considering that sST2 was associated with outcome in the more complex patients, one could speculate that the study population as a whole was not 'ill' enough, that is, in such a good clinical status that SST2 may not be of additional value in these patients. A study with symptomatic patients with ACHD would help to elucidate this question as well as longitudinal studies with repeated measurements of sST2. Furthermore, it would be of interest, if sST2 is of special value in specific congenital heart defects, for example, patients after the Fontan procedure or with a systemic right ventricle. These studies would probably benefit from a multicentre setting.

Geenen and colleagues study indicates that sST2 could indeed have a role as a biomarker in patients with ACHD. ${ }^{8}$ But before it can be used in daily clinical practice, remaining questions regarding the whom and when need to be answered first.

Funding The authors have not declared a specific grant for this research from any funding agency in the public, commercial or not-for-profit sectors.

Competing interests None declared.

Patient consent for publication Not required.

Provenance and peer review Commissioned; internally peer reviewed.

(C) Author(s) (or their employer(s)) 2019. No commercial re-use. See rights and permissions. Published by BMJ.

$$
\text { (D) Check for updates }
$$

To cite Tutarel O. Heart 2019;105:972.

Published Online First 12 March 2019

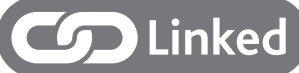

- http://dx.doi.org/10.1136/heartjnl-2018-314168

Heart 2019;105:972.

doi:10.1136/heartjnl-2019-314699

\section{REFERENCES}

1 Tutarel 0, Kempny A, Alonso-Gonzalez R, et al. Congenital heart disease beyond the age of 60 : emergence of a new population with high resource utilization, high morbidity, and high mortality. Eur Heart J 2014;35:725-32.

2 Engelings CC, Helm PC, Abdul-Khaliq H, et al. Cause of death in adults with congenital heart disease - an analysis of the German National Register for Congenital Heart Defects. Int J Cardiol 2016:211:31-6.

3 Eindhoven JA, van den Bosch AE, Jansen PR, et al. The usefulness of brain natriuretic peptide in complex congenital heart disease: a systematic review. J Am Coll Cardiol 2012:60:2140-9.

4 Tutarel O, Denecke A, Bode-Böger SM, et al. Asymmetrical dimethylarginine-more sensitive than NT-proBNP to diagnose heart failure in adults with congenital heart disease. PLoS One 2012;7:e33795

5 Aimo A, Vergaro G, Passino C, et al. Prognostic value of soluble suppression of tumorigenicity-2 in chronic heart failure: a meta-analysis. JACC Heart Fail 2017;5:280-6.

6 Maisel AS, Di Somma S. Do we need another heart failure biomarker: focus on soluble suppression of tumorigenicity 2 (sST2). Eur Heart J 2017;38:2325-33.

7 van Vark LC, Lesman-Leegte I, Baart SJ, et al. Prognostic value of serial ST2 measurements in patients with acute heart failure. J Am Coll Cardiol 2017;70:2378-88.

8 Geenen LW, Baggen VJM, van den Bosch AE, et al. Prognostic value of soluble ST2 in adults with congenital heart disease. Heart 2019;105:999-1006. 